UNIVERSITY of NORTH FLORIDA.

\section{Journal of Counseling Sexology \& Sexual} Wellness: Research, Practice, and Education

\title{
Sexuality Beyond Young Adulthood: Affordances and Barriers to Sexual Expression in the Nursing Home
}

\author{
Angela Schubert \\ Central Methodist University - College of Graduate \& Extended Studies \\ Mark Pope \\ University of Missouri - St. Louis
}

Follow this and additional works at: https://digitalcommons.unf.edu/jcssw

Part of the Counseling Commons, and the Mental and Social Health Commons

\section{Recommended Citation \\ Schubert, A., \& Pope, M. (2020). Sexuality Beyond Young Adulthood: Affordances and Barriers to Sexual Expression in the Nursing Home. Journal of Counseling Sexology \& Sexual Wellness: Research, Practice, and Education, 2 (1). https://doi.org/doi:10.34296/02011022}

This Article is brought to you for free and open access by the Brooks College of Health at UNF Digital Commons. It has been accepted for inclusion in Journal of Counseling Sexology \& Sexual Wellness: Research, Practice, and Education by an authorized administrator of UNF Digital Commons. For more information, please contact Digital Projects.

(C) 2020 All Rights Reserved

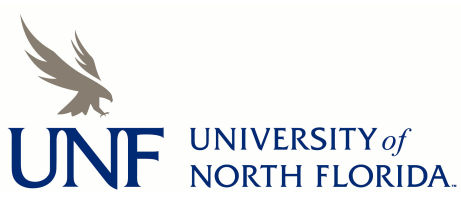




\title{
Sexuality Beyond Young Adulthood: Affordances and Barriers to Sexual Expression in the Nursing Home
}

\author{
Angela Schubert \\ Central Methodist University
}

\author{
Mark Pope \\ University of Missouri-St. Louis
}

\begin{abstract}
Human sexuality is part of life, regardless of age or place of residence. Previous research on older adult sexual expression in nursing homes-almost all of which was conducted using quantitative methods - has primarily focused on staff perceptions. This phenomenological study aimed to explore sexual expression as it was perceived, experienced, and practiced by ten older adults, ages 65 and older, residing in a nursing facility. This paper will explore themes associated with the self-perception of affordances and barriers to engage in sexual expression, and how mental health counselors may best serve the needs of older adults and advocate for affirming policies.
\end{abstract}

Keywords: older adult sexuality, nursing home resident, aging sexual expression

\section{Introduction}

Awareness and acceptance of sexual expression is growing for many populations in the United States; however, it is still seen as a social challenge faced by many older adults. For some reason, ageist views portraying older adults as disinterested or incapable of sexual expression continue to surface, regardless of how expressive and open people like Golden Girls actor and comedian, Betty White, prove to be. Betty White's commonly known, unapologetic attitude toward sexual expression is not the exception. Older adults continue to engage in sexual behavior and present with varying levels of desire until their last breaths. This presence of desire and yearning for physical affection, tenderness, and intimacy among older adults is well represented in the literature (Bell, Reissing, Henry, \& VanZuylen, 2017; Sousa, Dhingra, \& Sonavane, 2016; Lindau et al., 2007), and yet socially, adults are imagined to cross an invisible infantilizing line once they become older. One of the most common biases is that older people do not desire relational intimacy, physical intimacy, or engage in sexual activity. The consequences of such a misperception has led to social stigmatization of and nationwide ignorance about the older adult population. One major consequence of this stigma led to a jump in sexually transmitted diseases among the older adult population; according to the Sexually Transmitted Disease Surveillance report, there was a $16.7 \%$ increase in cases of syphilis from 2016 to 2017 among adults 65 and older in the United States (Centers for Disease Control and Prevention, 2018).

Regardless of this statistical reality, the social stigma tied to older adult sexual expression is not only streamlined by society but also internalized and expressed by many older adults themselves (Syme \& Cohn, 2015). For example, DeLamater and Moorman (2007) found older adults to hold the belief that sexual intimacy is only appropriate when occurring within marriage. Those who assume that this belief is true are often left without a sexual partner at the time of their spouse's death or as a result of divorce (DeLamater \& Moorman, 2007). The prevalence of such a belief regarding older adult sexual expression is only further complicated for many who end up residing in a residential facility. According to the U.S. Census Bureau (Roberts, Ogunwole, Blakeslee, \& Rabe, 2018), approximately 1.2 million adults, 65 and older, reside in nursing home facilities. Furthermore, the older adult population is expected to double by 2030 (Roberts et al., 2018). Therefore, the number of residents is expected to rise as well.

Attitudes toward older adult sexual expression have long been documented from the perspective of nursing home staff (Elias \& Ryan, 2011; Kehoe, 2013), but there is little data that reflects the narratives of the older adults who reside in nursing homes. Both qualitative and quantitative researchers on the topic of aging sexuality expressed the need for further research on nursing home residents and their interpretation of sexuality, desire, and sexual expression (DeLamater \& Sill, 2005; Elias \& Ryan, 2011). This paper aims to expound on

\begin{tabular}{|c|}
\hline Corresponding Author \\
\hline Angela Schubert \\
Central Methodist University \\
411 Central Methodist Square \\
Fayette, MO 65248 \\
E: aschuber@centralmethodist.edu \\
P: (720)235-8375 \\
\hline
\end{tabular}


the individual narratives of ten brave older adults residing in a nursing home setting, and to share how we as mental health professionals might better approach older adult sexual expression in the nursing homes through affirming policies and sex-positive education. A brief literature review of sexual expression specific to older adults will be addressed in the next section, including literature associated with the attitudes toward sexual expression in the nursing homes as perceived by residential staff.

\section{Literature Review}

In modern societies where youth and beauty are emphasized, older adults are more susceptible than their younger counterparts to receiving negative messages toward sexual expression (DeLamater \& Sill, 2005; Hajjar \& Kamel, 2004; Hillman, 2000). It is common in United States culture for older adults to be socially met with expectations to "act their age." As a result, older adults are far more likely to deny their own desire and correspondingly, to deny their own internal need for physical connection and intimacy (Laflin, 1996). Consequently, denying one's sexuality is also seen as having a negative impact on self-image, social relationships, and mental well-being (Hajjar \& Kamel, 2004; Hillman, 2000). Advocacy and support are necessary to prevent older adults from internalizing such messages. Considering the frequency in which older adults access healthcare, healthcare professionals are in an ideal position to support and advocate on behalf of their older adult clients and their sexual needs.

\section{Professional Preparation to Address Aging Sexual Con- cerns}

Healthcare professionals across fields can play a crucial role in the successful facilitation of sex-positive conversations by educating older adults on the topic of healthy sexual expression, and yet, across the healthcare profession, aging sexual expression continues to be perceived to be outside one's scope of practice (Haesler, Bauer, \& Fetherstonhaugh, 2016). Physicians are in the best position to monitor older adults for general medical concerns and to educate them about safe and healthy sexual practices. Nevertheless, studies have shown that general physicians often believe they do not have a thorough understanding or expert knowledge on aging sexual expression (Hughes \& Wittmann, 2014) and struggle to initiate conversations with older patients on the topic of sexuality (Levkovich, Gewirtz-Meydan, Karkabi, \& Ayalon, 2018).

Mental health counselors are also in a unique position to explore sexual concerns with and provide thorough sex education to older clients; nevertheless, most counselors are not adequately trained to address sexuality in counseling, regardless of age demographic (Zeglin, Dam, \& Hergenrather, 2017). Counseling could provide a wonderful opportunity for older adult clients to explore their own sexual narratives and examine generational differences in sexual beliefs and practices - if counselors receive the proper training (Watters \& Boyd, 2009; Williams et al., 2016). Kehoe (2013) further stated that long-term care facilities are in need of mental health counselors, not only to support the mental health concerns of the residents, but also to advocate for affirming policies and integrated care. This could include sex-affirming policies, but nursing homes and their staff struggle to see how to best support the sexual needs of the older adults residing in their care (Metzger, 2017).

\section{Nursing Home Attitudes Toward Aging Sexual Expres- sion}

Nursing homes were established to provide refuge for and protect the most vulnerable. With medical and safety needs at the forefront, sexual expression was not considered a viable factor when compared to other medical and environmental needs. As a result, much focus on sexual expression within the nursing homes is limited to addressing nonconsensual sexual behavior and diminished capacity to consent. Although not every resident at a nursing home has some form of dementia, this neurodegenerative disorder with an 80 percent behavioral disturbance rate poses a potentially great threat to individuals residing in nursing home facilities (Mahieu \& Gastmans, 2011).

Due to the consensual nature of sexual activity, it is understood why there is a proliferation of literature on the topic of consensual sexual expression and dementia (Archibald, 2002; Elias \& Ryan, 2011; Mahieu \& Gastmans, 2011). Although it is critical to protect all persons residing in nursing homes, such focus often results in both implicit and explicit bias toward resident sexual expression (Doll, 2013; Knaplund, 2015). A study reviewing current legal documents and nursing home policies related to privacy rights of residents found a similar outcome in that healthy sexual behaviors exhibited by older adults were considered "sexually inappropriate behavior" by the nursing home staff (Knaplund, 2015). Knaplund (2015) reported that "seniors in nursing homes are lectured and ridiculed, even transferred involuntarily, for having a sexual relationship" (p. 248).

\section{Older Adult Attitudes Toward Aging Sexual Expression}

Research has shown that socially conservative older adults are more highly critical of their sexual selves and hold a higher degree of sexual guilt (Hudson, Murphy, \& Nurius, 1983; Laflin, 1996; Syme \& Cohn, 2015). Those with more socially conservative attitudes are inclined to internalize negative societal messages (DeLamater \& Sill, 2005) and, as a result, deny their sexual needs. Internalized ageism toward sexual expression may be exacerbated by the natural response of the aging body to sexual expression. Considering desirability and social standards, chronic illness may be 
especially distressing to a person's confidence and sense of sexual well-being (Laflin, 1996).

As social beings, people are inclined to look to partners and older peers and adults for knowledge and social guidance. As people grow older, sharing of knowledge is limited and vulnerable people may become more susceptible to complying with current societal cues and beliefs toward aging sexual expression. For example, if a society proclaims that sexuality is primarily for the youth or for procreation purposes, older adults with diminished ego strength and lack of positive role models may intrapersonally communicate negative messages toward their own sexual desires and interests. As a result, older adults are susceptible to seeing themselves as sexually deviant for experiencing desire, or as asexual after experiencing diminished sexual desire. In societies where messages of beauty, health, and sex are ascribed to young people, older adults are challenged with their own sense of beauty and sexuality.

Due to social stigma and internalized ageism (whether perceived or experienced), older adults have difficulty addressing sexual concerns with others interpersonally. In the Lindau et al. (2007) study, only 38 percent $(n=927)$ of the male participants and 22 percent $(n=1,058)$ of the female participants (65 years of age and older) reported discussing sexual issues with their physician. The same participants reported that they had not discussed sexual issues with a physician since they were 55 years old.

\section{Prevalence of Sexual Interest}

Sexual activity is often defined as sexual intercourse, but a broader definition is more applicable to most individuals. Although sexual activity declines with age, men and women in their 80s and 90s report being actively engaged in a variety of sexual activities, including vaginal intercourse, oral sex, and masturbation (Lindau et al., 2007). Interest in sex does not necessarily diminish with admission to a care home, though frequency of engagement in sexual behavior has shown to decrease (Solway, Clark, Singer, Kirch, \& Malani, 2018; Elias \& Ryan, 2011; Mulligan \& Palguta, 1991). Older adults may resign themselves to celibacy if they deem sex unnecessary or if proscribed moral values conflict with internal desire to achieve sexual gratification (Muzacz \& Akinsulure-Smith, 2013).

According to Hillman (2000), research on later life sexual expression supported the construct of desire related to personal motivation, needs, and satisfaction among older adults. Hillman reported that in later stages of life, desire may actually be positively associated with biopsychosocial constructs, such as

fostering of emotional intimacy; experiencing and enjoying physical pleasure; satisfying continuing biological urges; asserting independence and experimenting new things; feeling youthful; challenging societal myths; reestablishing societal myths; heighten bodily awareness; and engender comfort and familiarity with the changing body (p. 18).

Although the body undergoes several changes over the course of time, the literature still suggests that sexual desire remains an important aspect of life for the older adult (DeLamater \& Sill, 2005; Hajjar \& Kamel, 2004; Hillman, 2000; Masters, Johnson, \& Kolodny, 1994).

\section{Problem Statement and Purpose}

Few studies have captured the residents' individual experiences within the nursing home as it pertains to sexual expression and positive sexuality. Given the lack of research, how nursing home residents access opportunities to express themselves sexually and intimately merits consideration. Since their inception, nursing homes have gone through several transformations to meet the needs of their ever-growing resident population. For many nursing homes, policy and care procedures have focused on medical needs and quality environmental standards. Sexual expression, however, is a quality of life indicator that has not been well researched or considered in nursing homes in general. Sexual expression is influenced by intrapersonal, interpersonal, cultural, and psychological factors (Doll, 2013) and remains an important component to life throughout the lifespan for many people.

Similar to residents of the first nursing homes created in 1939, individuals who take refuge in a nursing home often do so out of fear of becoming a burden to family or because there is no one in the family able to care for them (Beeber, 2011). The "choice" to move into a nursing home is often seen by older adults as their last resort, for fear of nursing staff neglect, loss of independence, and loss of normalcy of private home life, including intimate engagement (Beeber, 2011). According to the results of this study, challenges most often experienced by the older adult population may result in clarifying aging sexual expression and restructuring of policy on the topic of privacy rights and sexual expression among older adult residents in nursing homes.

\section{Methods}

The purpose of this phenomenological qualitative study was to explore the unique attitudes, values, and experiences of older adult residents regarding the issue of physical and relational intimacy and sexual expression in a nursing home residential setting. The research design and method was used to explore if, how, and under what circumstances, older adult residents felt comfortable with sexual expression in the nursing home setting. This study hoped to document the 
"essence" (Moustakas, 1994) of being an older adult desiring connection and intimacy within a nursing home environment, especially exploring the "inner experiences un-probed in everyday life" (Merriam, 2002, p. 7) of these older adult residents.

\section{Recruitment}

Nursing home facilities in the Midwest were selected based on length of establishment (ten years or older) and state licensure to ensure quality of site and longevity of practices. Facilities in the designated area were contacted and permission was requested to conduct the study at their respective facilities. Of the 13 nursing homes identified, two nursing homes agreed to participate in the study. Both nursing homes were located in a rural region. In addition to meeting the criteria, both nursing homes reported to have a policy on resident sexual aggression and one reported to have a specific policy on sexual expression; however, staff were not allowed to share the policy manual with non-employees.

The researcher presented the study to the resident population before meal time in the community space and those interested in the study met with the researcher after the presentation. Residents were interviewed separately at a location in the nursing home that was most convenient to them. A private setting away from both staff and other residents was vital to prevent residents from feeling confined to their setting.

\section{Participants}

Smith and Osborn (2008) prefaced phenomenological data analysis to be so rigorous that it could only be conducted appropriately when collecting data from a small sample size, especially when approaching this type of research for the first time (Smith, 2008). This study sought to identify ten residents who met three specific criteria. Resident participants met the age requirement of 65 years and older. The approved residents scored a 27 or above on the Mini-Mental State Exam (MMSE). Saturation was achieved after six residents; however, the researcher decided to interview a total of ten residents $($ men $=6$; women $=4$ ) in hope of increasing diversity among the sample and increasing the number of female resident participants in the sample. To maintain confidentiality, researchers provided each participant with a pseudonym: Harry, Sally, Bonnie, Clyde, George, Alma, Jackson, Buddy, Ginny, and Chuck (see Table 1).

\section{Interviews}

Semi-structured interviews were utilized to explore the narratives of the ten resident participants. Seidman's (2013) interviewing process was adapted to interview each participant. General questions on the subject of sexual expression were utilized in order to prevent leading the conversation or overly guiding the responses. The researcher met and interviewed the resident participants two different times, approximately three days apart. The first interview focused on the life story of the participant and lasted 15 to 30 minutes. The second interview focused more on the participant's reported sexual experiences and interest in intimacy and sexual expression. The length of the second interview was 45 to 60 minutes. The participants were interviewed in the privacy of their own room at their respective nursing home facilities. Although the narratives contained several similar themes, the stories were unique and emerged from each individual's life experiences, involving relationships and understanding of oneself as a sexual being. The semi-structured script for the second interview included the following questions:

- If you have or had a partner, in what ways has your sexual relationship evolved or changed as you have aged?

- How would you describe your sense of pleasure and fantasy?

- Can you describe your interest in self-stimulation?

- What do you dress up for? Perfume, make-up, etc.?

- What are some messages you have received about intimate expression in the nursing home? Both pro and con...

- In what ways are people here involved in romantic relationships? How does that work for them? If any, what kind of issues do they experience in expressing their care for one another?

- What are some ways that you and the people you know express their sexual selves?

- How willing are people to talk about their sexual needs with one another? With staff? With family?

- If applicable, how have your relationships changed since you moved into a nursing home? Especially in terms of touching and sexual expression?

\section{Analysis}

The process of this study followed a developmental format of qualitative data collection. The development of the study was a "heuristic process through which one discovered the nature and meaning of experience and developed methods and procedures for further investigation and analysis" (Moustakas, 1994, p. 17). Through constant comparative analysis, each step of the data collection process built upon previous data as patterns emerged (Merriam, 2002). This process deepened understandings of the nursing home 
Table 1

\begin{tabular}{llllll}
\multicolumn{2}{l}{ Participant Demographics } \\
\hline Name & Race & Age & Gender & Sexual Orientation & Living Situation \\
\hline George & White & $85-89$ & Male & Straight & Private \\
Alma & White & $80-84$ & Female & Straight & Private \\
Harry & White & $90-94$ & Male & Party Bisexual & Private w/ Spouse \\
Sally & White & $90-94$ & Female & Straight & Private w/ Spouse \\
Buddy & White & $75-79$ & Male & Straight & Private \\
Jackson & White & $85-89$ & Male & Straight & Roommate \\
Clyde & White & $90-94$ & Male & Straight & Private w/ Spouse \\
Bonnie & White & $90-94$ & Female & Straight & Private w/ Spouse \\
Ginny & Cherokee Indian & $90-94$ & Female & Straight & Roommate \\
Chuck & White & $90-94$ & Male & Straight & Roommate \\
\hline
\end{tabular}

experience as lived by the residents. The phenomenological reduction of data analysis in interpretative phenomenological analysis required the researcher to interact with the data through a three-step process according to Smith and Osborn (2008): bracketing, horizontalization, and clustering of meanings or superordinate themes.

The goal of the study was to focus on the experiences of the four women and six men who resided in a nursing home, reflecting on each individual's sense of intimate expression and sense of self as a sexual being. The meanings residents attribute to those aspects of their personhood were explored. The aim was to compare and contrast each individual account, and to successfully capture each individual's process of self-identification as a sexual being (or loss of such identity) as a result of aging, illness, relationship status, and nursing home environment. Each participant's account was clearly unique and ever changing; the perception of self as a sexual being had inevitably evolved over time for all participants.

Trustworthiness was established through four strategies: dependability, confirmability, credibility, and triangulation. Dependability was assessed through the researcher's report of any changes that might have affected the way the researcher approached the study and, moreover, the way the participant engaged in the study. Confirmability, "the degree to which the results could be confirmed or corroborated by others" (Blash, 2010, p. 85) was completed by the participants themselves. Each interview was recorded and later transcribed. Completed transcriptions of individual interviews were offered to participants for verification. Due to the sensitive nature of the material, the member check also allowed participants to identify any passages that they felt were too personal. Every effort was made to respect any request for an exclusion of certain passages from the data; however, no one requested such exclusions.

Credibility was assessed through engagement, persistent observations, triangulation, and member checking. Engagement is the process by which the researcher remains in the study collecting data until saturation occurs (Merriam,
2002). Finally, triangulation was achieved by means of selfreflexivity and examination of the data derived from resident participants, field notes, and reflections. This process identified key biases of the researcher by means of bracketing researcher background and experience with the topic.

\section{Results}

Interview questions and conversations were used to explore comfort on the topic of and expression related to sexual intimacy presented by residents. This paper will address a section of the themes identified in the study specific to affordances and barriers perceived by residents related to sexual expression. Autonomy, as well as the pleasures of a normal daily lifestyle, are challenged as people transition from their own home to a nursing home. Comfort in doing personal and private things are equally challenged. Daily activities such as using the restroom, bathing, and changing oneself become shared responsibilities with nursing staff, who are at least initially considered strangers. Activities such as masturbation, mutual touching, embracing, kissing, intercourse, and other types of sexual engagement also become challenging and may be perceived as too risky to engage in for many individuals transitioning to a residential community setting such as a nursing home. The superordinate themes associated with affordances and barriers were identified as the following: privacy and support, resident attitude toward sexual expression, resident knowledge of sexual expression policies, opportunities to date, comfort with sexual discussion, and perceived status as a guest.

\section{Affordances to Healthy Sexual Expression}

Privacy and staff support. Privacy, along with dignity, is considered one of the most important components to overall quality of life in nursing homes. It was important, then, to explore whether participants experienced privacy in the nursing home setting, and to what degree privacy was afforded. Along with privacy, opportunity was also explored in relation to whether participants perceived opportunities to engage in 
sexual expression. In this study, privacy and support were each identified as both a barrier and an affordance. Some perceived a great deal of privacy and opportunity and some did not. This section focuses on those participants who perceived privacy as an opportunity and a limitation, and how staff supported (or did not support) opportunities for the resident participants. Harry was one of the participants who reported staff as supportive. For example, Harry and Sally engage in a morning intimacy ritual that starts with a prayer and ends with staff knocking on the door:

Usually we have a clock on the ceiling. And when it is 6:00, I'll say "Six" and I'll wait until she starts it, but she may not feel like doing it again. One of us then will say, "Good morning honey, I love you." And the other will answer, "This is the day in which the Lord has made," and so on. We'll talk about what day it is and all of that. We'll maybe talk about what we are going to have to be doing today, or talk about yesterday, or talk about what kind of a night we had. And then after a while, someone will come in wanting to know what we want for breakfast and they'll take it down and then they will come in. (Harry, Lines 249-253)

The details of this excerpt suggest a loving ritual between both Harry and Sally. Despite its briefness (approximately 10 minutes), Harry and Sally reported feeling overall satisfied with the time. Harry and Sally also have a nighttime ritual, similar to their morning one, that is supported by staff. Sally explained:

We, every night just before we are ready to have the aides come and help us get to bed, we close our door and turn the lights out except for one and have about oh, 10 to 15 minutes together, and when we turn our call light on, they come and put us to bed. (Sally, Lines 195-198)

Harry and Sally perceived staff to be very supportive but they also made intimacy and private time a priority and advocated their needs with the staff.

Bonnie and Clyde were interviewed together. When asked if they felt that privacy was available for both to be intimate, Clyde reported jokingly, "We can do what we want in it, except murder each other" (Clyde, 137). Bonnie suggested the same: "I'd say we could pretty much do anything we want to do" (Bonnie, Line 594). Both then clarified, "We can do anything, but we don't do anything" (Clyde, Line 596). Bonnie then reported with a tone of acceptance, "That's the way life is when you get to be 91 in a resident facility" (Bonnie, Line 600).

Although considered limited by all participants, privacy was seen as an affordance to a certain degree. Many of the participants recognized the importance of medical needs and nursing responsibilities as an expectation of the nursing home experience. Although privacy was limited, they were able to identify moments and private opportunities to be by themselves and to be with each other. Beyond their bedroom, Sally and Harry both described other opportunities for intimate expression. Sally explained, "Every once in a while, even in the dining room or anywhere, if one of us want to, we say, 'I love you', and he'll say something similar back" (Sally, Lines 287-288). Sally also explained how they also took advantage of the outings provided by the nursing home, to be together and enjoy the community. Bonnie and Clyde, too, reported participation in the nursing home outings: "We like to go to the movies and shop and people-watch" (Bonnie, 383). The majority of the participants, in fact, reported frequent participation in community outings. Many desired to leave the nursing home on occasion.

Opportunities to be with his spouse privately and publicly were also considered very important to Jackson, whose wife could visit him only weekly. Jackson explained:

We like to spend time by ourselves when we go up [to the dining hall] or eat here or go out some place. The few hours that we spend together we like to be together to just talk and play cards (Jackson, Lines 509-511).

George, who lived in a private room, explained how he used his privacy to fulfill his sexual needs in the evening hours. As he walked to show me his collection of DVDs, George explained, "I got some sexy movies over there I watch and sometimes that stirs me up" (George, Line 930). When asked if staff supported his decision to view such movies, he clarified, "They leave me alone pretty well after 11:00pm. And I can watch them later at night" (George, Lines 938-946). From these disclosures, George believed the nursing home would not allow pornographic movies, but he did not ask before relocating to the nursing home. He simply became comfortable and confident enough to "risk being caught" with the videos. Intriguingly, there was a sense of excitement experienced by George of getting caught in the act of watching the films. From George's experience, the staff provided the opportunity of privacy and knocking as a demonstration of acceptance of his sexual needs.

Resident attitude toward sexual expression. Questions and conversations centered on individual perception of how others in the nursing home expressed themselves sexually or intimately, and on what the residents thought about those narratives. Participants reported either a positive or negative attitude toward others in the nursing home in relation to sexual expression, intimacy, and relationships. This dichotomy reflects the participants' liberal or conservative attitudes toward sexual expression. Harry exclaimed, "They've got to touch each other!" (Harry, Line 922) When asked to 
further explain, Harry clarified, "They need to feel loved. To touch someone and to be touched. Not a stranger but they need to feel connected to someone they love" (Harry, Line 926-927).

Jackson also expressed a positive attitude toward a romance in the nursing home: I think it's so nice-one of the men-it's a storybook romance. She just came in here. She was a nurse-this was back in World War II, he was injured, he came into the hospital and they got together. She was of course, a lieutenant and they weren't supposed to be doing anything and I guess had to hide their feelings and so forth. She came in here last month or so but he hadn't been in there too long himself but they were able to be together, which is so nice. (Jackson, Lines 907-914)

He then reflected on his own romance and lamented, "I'd give anything if my wife could be right on the other side of that [pointing to the other side of the room]" (Jackson, Lines 913-914).

Bonnie shared a story of a woman who did not need to be in the nursing home, but who moved there to be with her husband who needed the medical assistance. The husband, as Bonnie explained, was someone who could no longer talk and who was not consciously aware of what was happening around him. She explained, "She sold her home and moved here-I think that's what I call true devotion in a marriage" (Bonnie, Lines 353-354).

George mockingly described a male resident and a female resident who frequently visited each other in the night. Although he expressed a positive attitude toward the midnight rendezvous, he also suggested that he was "jealous." Alma and Ginny shared a similar ambivalent response toward others' interest in intimacy. Alma explained that some residents have reported loneliness as a reason for establishing a relationship in the nursing home: "They always say well we are both lonely and that's all that is to it. That's fine with me" (Alma, Lines 588-589).

From the perspective of the nursing home residents, affordances to sexual expression were both experienced and perceived by others as part of their nursing home experience. Privacy was afforded to a certain degree in George's case as he was provided a "Privacy, please" door hanger by the nursing home staff. Per resident request, all residents at his facility were able to receive the door hanger. Some resident participants observed others in the nursing home being intimately expressive, and defined sexual expression in their own way: a kiss, a hug, a midnight rendezvous, and a longterm decision to move into a home just to be with their ailing partner. Although privacy and opportunity was considered available, all participants (including the ones in this section) reported that their privacy was no longer the same as it had been when they lived on their own.

\section{Barriers to Healthy Sexual Expression}

Resident knowledge of sexual expression policies. This theme represented the lack of clear knowledge on resident sexual expression, as reported by resident participants. None of the ten residents could clearly identify specific policies, protocols, or procedures regarding resident sexual expression or cohabitation in the same room. Some participants, like Alma, speculated that policies existed only for heterosexual married couples: "I think that is just-unless they are a husband and a wife-you know" (Alma, Line 584). Chuck also made the same suggestion: "Nope. Not offhand. They don't like it available to you unless you are married and if you are married, well you can get a room here for your wife" (Chuck, Lines 662-663). Ginny, Harry, Buddy, Jackson, and Sally reported that policies were never discussed with them. Bonnie and Clyde explained, "They just made sure we got a room together. There was no rules or regulations or anything like that about living together, at least I think so" (Bonnie, Lines 588-589).

There are several important issues to note within these brief disclosures. In the absence of a clear policy on sexual expression (i.e., married couples are permitted to be intimate but single adults are not), residents made assumptions and guesses about the topic of sexual expression. Because of the lack of policy, participants believed that opportunities for sexual engagement were afforded exclusively to married couples. Residents also believed that adults without a partner were either expected to marry, live out their residential lives without a sexual partner, or engage in sexual acts with the possibility of going against a possible policy. George and Chuck desired to be with a woman, but perceiving limited opportunity to meet someone in the community, felt restricted to the women who resided in their nursing home. Although the married couples believed it was appropriate for them to engage in sexual activities, they were unsure of specific policies and, therefore, had to assert their sexual stance with the idea that they may be at risk for discipline. Harry, for example, asserted that "When we can, we get together and kiss. We don't mind being caught doing that" (Harry, Lines 1146-1147).

Limited opportunities to date. It was important to explore whether participants believed that opportunities existed to meet potential partners and/or participate in intimate outings. Lack of transportation and personal vehicles was considered an issue for those interested in meeting new people. Both nursing homes offered a variety of social activities, such as playing bingo, for resident enjoyment. George also identified bingo as one of the social activities offered by the nursing home. When asked if he participated, George replied, "I did, but I kind of got - it got a little monotonous" (George, Line 1684). When asked if he was ever attracted to someone while 
playing bingo, he responded, "No. Usually the only people playing is the people that are living in here. And most of them are old" (George, Line 1688). Later, George was asked if other social opportunities were presented by the nursing home to meet people and he exclaimed, "I don't know, I'm just kind of wandering around in the dark on that kind of stuff" (George, Line 1084-1085). According to George, the nursing home provided little to no opportunities to meet a woman in the community-beyond the nursing staff.

George's concerns were shared by Chuck as well. After Chuck's second wife died, he described a desire to be with someone; however, he could not foresee the possibility: "Well yeah it's been a tough year. I lost two wives and-that I got pleasure from all the time. I don't know. Maybe it was meant that way. I don't know" (Chuck, Lines 811-812). As earlier stated, only four women lived in the resident home where Chuck resided and because of this, he also saw limited opportunities to meet new women.

Of those in relationships, four out of five participants reported interest and frequent engagement in social activities in which they would participate with their spouses. Sally also commented that there were no real opportunities to go on a date with her spouse: "Not since we've been here. What could we do on a date?" (Sally, Line 552). She and her husband explained that they used to engage in hobbies such as gardening, cooking, and music. Although they were able to bring their music with them, they both reported how much they missed working together in a garden or cooking in the kitchen-neither of which were offered at the nursing home where they resided.

Limited privacy and autonomy. Although many nursing homes enforce laws that mandate affordances such as privacy rights for residents, realistic limitations exist with regard to the extent of privacy. To fulfill the variety of unique needs, nursing homes employ a variety of people: nursing assistants, social workers, counselors, nurses, physicians, maintenance workers, housekeeping staff, dieticians, cooking staff, administrators, and more. Each of the aforementioned employees, depending on the need, has access and clearance to enter the resident's room when necessary. All ten resident participants reported that privacy was limited and that disruptions appeared inevitable.

A few participants accepted the limited privacy, but many reported feelings of frustration with the ongoing disruptions that occurred in a given day. Some participants equated the disruptions with the reason for limited engagement in intimacy with spouses, and/or with oneself. Although George frequently viewed pornographic material while masturbating before he moved into the nursing home, this uncertainty of approval and opportunity left him with the decision to get rid of his collection: "Well I figured they would [staff would be bothered] when I came in. I got rid of all my movies like that before I come down here. I bought them since I've been here" (George, Lines 959-960). At one point, the nurse walked in while he was watching one of his videos and he commented on his concern for her: "She was startled and I was worried I would get in trouble. She didn't say anything to me but she left shortly after giving my medicine." Because he did not know when staff would come in, he restricted his viewing to the evening hours: "I usually don't watch them during the early hours" (George, Line 985); "Now there'd be something happening [on the video]-I wouldn't want to upset—but they're used to kind of things like that, I think. Well it depends on who it is, but some of them wouldn't mind" (George, Lines 993-994).

All participants described respect of privacy as limited to a knock at the door upon entrance to their room. When questioned about opportunities to be intimate, both Bonnie and Clyde laughed. Clyde explained, "In the first place you can't have any thoughts of sex because anytime somebody might knock on the door and walk right in" (Clyde, Lines 228-230). Although Harry and Sally deemed their 10 to 15 minutes of privacy as "sufficient" to engage in their evening intimacy ritual, Harry also clarified that opportunities for a spontaneous and privately intimate moment with his spouse, Sally, were practically an impossibility: "That's the only time we really have that's intimate. Because other times it would be possible" (Harry , Lines 203-204). When asked to clarify, he suggested, "People [staff] coming in and out. There is no lock on the doors. No doors have a lock" (Harry, Lines 212-213), and "They'll knock, but they come in instantly" (Harry, Line 218).

One of the other challenges perceived by Sally, specifically, involved the amount of time she spent together with her husband. According to Sally, there was not much of an opportunity for her to have space and privacy away from her husband. Sally explained, "Through the years, we've given each other time of our own when we wanted it. Now, we haven't been separate from each other for more than two weeks at a time" (Sally, Lines 267-269). Both Sally and Harry described a deep symbiotic fondness for one another and, at the same time, they recognized their human desire to be away from each other for a period of time. As a result of living in the nursing home, they were restricted to their environment and to the confines of the nursing home.

The limited opportunities for privacy, as perceived by residents, appeared to restrict the prospect of spontaneity and autonomy. It could also be suggested that a level of acceptance with regard to limited privacy was a result of the establishment. Many participants reported expectations of the nursing home as a place for medical needs to be treated; privacy was expected to a certain degree but could not be compared to living independently.

Comfort level with sexual discussion with staff and doctors. In order to understand how residents perceived opportunity to communicate their sexual needs and concerns 
with staff, it was important to explore the level of comfort regarding sexual discussion with staff, physicians, and family. All ten residents declined to ever discuss sexual concerns with staff, physicians, or family members. Most participants reported discomfort with the idea of discussing their sexual needs and concerns with staff, physicians, and family members. Even though George was a former friend of the administrator, he admitted, "I'm, not very comfortable-I would ask the nurse more than I would ask the administrator. Not about sex. I've known her a long time. I knew her before I come up here" (George, Lines 2023-3034).

Chuck was the only participant who described an interest in discussing sexual desires, needs, and concerns with staff and physicians but explained that he was unsure of how to go about it: "I guess I'm reasonably open to do it. But I don't know. I haven't spoken to these ladies [nursing staff] about it" (Chuck, Lines 721-722). When asked if he could identify someone at the nursing home with whom to discuss sexual needs and/or concerns, Chuck explained, "Not necessarily. Well, I take that back. I talked to them about their family relations and their divorces. I don't know what to say. I can't put it in words. For some reason or other" (Chuck, Lines 726-728). Although he never discussed sexual concerns with his physician, he clarified that as a result of the interview he was interested in learning more about other alternatives to meet sexual needs: "Well you stirred up my appetite for doing something. You did that. By making suggestions when you asked me whether I had done this or done that and I hadn't" (Chuck, Lines 750-751). Although two participants experienced erectile difficulties after the death of their spouses, one considered discussion meaningless without a partner. George dismissed the possibility of having a sexual discussion with a physician because "I wouldn't even know what to do if [I could]" (Line 2171). Comfort level discussing sexual concerns and interests was considered a perceived barrier because not one resident had discussed sexual concerns and/or interests with those who cared for them, whether they were staff, physicians, or family members.

Be our guest. The residents in this study did not desire to move into the nursing home, but were forced to do so after several attempts of living on their own proved too difficult. As one might feel when staying at a friend's house, many of the participants felt like guests in the nursing home. Alma explained, "Why would people be interested in doing that here? This is not their old house" (Line 485). As a result, the interest in opportunity to voice a thought or opinion regarding sexual expression seemed unnecessary, as intimacy was not considered the primary reason for their stay. This constant state of tension exists when hospitality is challenged by the hospital setting. Residents are often enticed by "home away from home" mission statements with the knowledge that privacy and independence will potentially be limited to some degree as a natural result of the nursing home environment.
When a person transitions into a nursing home, it is conceivable that they may have already surrendered their independence to a certain degree. Clyde further explained when discussing couples consisting of one partner who resides in the nursing home and one who still lives at home: "I look at a lot of people around here that are married and their wives come to visit-I wonder what their sex life was like. It's over. I know that. They ain't going to crawl in bed when he's in here" (Lines 338-340). When discussing his deceased wife and how they lived in separate rooms at the nursing home, George explained: "It bothered me to, you know, to have her that close and couldn't do what I wanted to" (Lines 15571558). In fear of becoming too much of a burden or in fear of being perceived as a "deviant" according to George, these resident participants chose silence.

\section{Findings Summary}

Barriers described in this section, regardless of whether they were perceived or actual, were considered to be true obstacles for those in this study. Some participants were more affected by the barriers than others. Transportation, privacy, opportunity, and access could be considered typical affordances for many individuals in the community, but for many of the participants in this study, those resources and opportunities were believed to be limited to those outside of the nursing home.

Some residents were able to creatively identify opportunities (though limited in several ways) and yet, for some single residents, the limitations of the opportunity both to meet new people and to participate in dating were described as frustrating and hopeless. Inevitably, the continued lack of social opportunities decreased the individuals' perception of hope for another chance at love. George and Chuck, specifically, identified the barrier of social opportunity as one of the most significant dilemmas in their nursing home.

Privacy was also considered a significant barrier to residents. The setup of a standard nursing home room is often open and occupied by multiple residents, making it quite difficult for respective residents to have private space and distance themselves from each other (Hajjar \& Kamel, 2004). Those with roommates had very little privacy, and even for those who occupied single rooms, the privacy was extremely limited, and disruptions were constant throughout the day. The Resident Bill of Rights emphasized the civil liberties of the residents to include personal dignity, individuality, and privacy, and to any person of their choice (Voice, 2019).

These constructs were reported by the residents in this study; however, what the Resident Bill of Rights does not clarify is the degree of privacy or length of private visits. In the case of Harry and Sally, they limited their opportunity of privacy and intimacy with each other to a minimum of ten minutes not to exceed 15 minutes every morning and evening. Although the time was not mandated by the nursing 
home, the residents believed it was the only opportunity they had for intimacy - an agreement made between nursing staff and the couple. This perception of limitation and lack of privacy was experienced negatively by several residents. These findings are consistent with Mulligan and Palguta (1991), who explained that couples who reside in nursing homes are highly susceptible to feeling frustrated and emotionally and physically deprived as a result of lack of privacy, and/or negative attitudes of staff and family toward sexual expression.

\section{Reflexivity and Interpretative Discussion}

A reflexive journal was used to document elements considered important and possibly related to the narratives. Reflexivity is the awareness that "all knowledge is affected by the social conditions under which it is produced; it is grounded in both the social location and the social biography of the observer and the observed" (Mann \& Kelley, 1997, p. 392).

Excerpts from the reflexive journal were helpful in the interpretation of the findings. For example, privacy was seen as a major barrier for almost all participants. Each participant acknowledged limited privacy. It was apparent that privacy was indeed an issue during the interviews. I interviewed each person sequentially. Each interview was interrupted at least once and some interviews were disrupted multiple times. The disruptions were distracting to some of the participants and appeared not to bother others. A few participants were embarrassed by the disruptions and apologized repeatedly to the researcher. I cannot imagine how difficult it would be to attempt to engage in any type of self-stimulation or foreplay with another person.

Beyond privacy, the narratives of these individuals convey a story of survival, humanity, and acceptance. The nursing home is a constant reminder of mortality, from the wailing cries of other residents down the hall to the congested hallways crowded with human beings sitting in wheelchairs, some barely able to speak. One of the more existential challenges faced by nursing home residents was the experience of incredible tangible and symbolic loss. The loss each resident in this study had experienced was tremendous. For some it was the loss of friends, lovers, children, and even their independence. For others it was the loss of their identity as a spouse and lover. Some participants chose isolation, some gave up on the possibility of future romantic relationships, and some chose to live out their final days in the confines of the nursing home. Others desired to be connected intimately to another person again.

Those who yearned for love and intimacy appeared disenfranchised in their attempts to pursue a love they believed appropriate. Harry's fondness for the nurse was met with mocking sweetness by the administrator until he later revealed his desire to bury his face in the nurse's hair. The administrator discouraged him from engaging with the nurse again but shortly after that conversation, the nurse quit her job. Harry explained "So we had to back it down. We still got along with each other, but wasn't long, she left. Boy, that hurt" (Harry, Line 318-319). Regardless of the reality of the nursing home environment, some perceived staff care as therapeutic and others perceived staff behavior (kisses, hugs, and sweet words) as intimate opportunities, as in Harry's case. Although it is unclear how nurse behavior was actually presented with residents, almost every single resident in this study reported being kissed (on the cheek, forehead, and the back of the neck) and hugged by staff.

Of the five participants who were married, each had a unique perspective of life after transitioning into the nursing home. Sally and Harry both desired to sleep in a single bed together, and yet medical conditions prevented them from doing so. Moreover, Sally was apprised of Harry's feelings toward the nurse and after decades of marriage, this new relationship was celebrated by both Sally and Harry. Although there was no doubt they still desired to be with one another, Harry explained that Sally was there through it all, even before he let the nurse know about his feelings: "She knew that, every time, Sally knew it. I kept her informed. And Sally has been a wonderful person about it" (Harry Lines 392-393).

Two couples lived together. The rooms were typically crowded with dressers and trunks full of what remained of a person's lifetime. Sally expressed a need to be separate from Harry, even for just a few days. Prior to moving in, they had been together but not always in the same room. Although Bonnie did not need to move into the nursing home, she did so in order to be closer to her husband. They did not need a single bed; they simply needed to be in the same room. Bonnie chose her husband, perhaps for the very same reason that Jackson yearns to die at the same time as his wife. They could not live without each other.

\section{Implications for Mental Health Counselors and the Nursing Homes}

The need for counselors continues to increase as the older adult population grows, especially for those who reside in nursing home facilities (Maples \& Abney, 2006). Older adults are not a homogenous group of people, and as found in the narratives in this study, their thoughts on sexuality and growing older vary from person to person. Adults undergo a huge transition when moving from an independent dwelling to a residential setting, which can cause a great deal of mental distress and confusion. Beyond their basic needs to live, they may even feel uncertain about how intimately authentic they can truly be in a residential setting, especially if they identify themselves as more or less a "guest" in someone else's house.

As the nursing home population grows, so does the need for counselors who are trained to serve the mental health and sexual wellness needs of this particular population. Counselors are trained to advocate on behalf of the client, so what 
do they need in order to best serve and advocate for the older adult resident? Most counseling programs, beyond one lifespan development course, do not offer the appropriate training to properly serve older adults and their mental health needs. Licensed counselors can serve as mental health liaisons and counselors in nursing home settings; therefore, it would greatly benefit both the students and their field to incorporate more specific training on aging development and aging sexual expression.

This study found that many residents perceived more limitations than affordances concerning personal sexual expression and engagement in sexual practices. The lack of both knowledge on specific policy and comfort with sexual discussion may also act as a barrier to residents' ability to feel fully supported and comfortable in expressing their sexual selves. This study illuminates the need to increase education, training, and awareness of aging sexual expression and how such expression may be embraced and supported by the nursing home facility, staff, residents, and counselors. The ability to encourage clients to have a voice in the nursing home setting is especially important considering the results of this study. Kampfe (Kampfe, 2015) explained in her book Counseling Older Adults: Opportunities and Challenges, that counselors are the best choice for older adults because counselors are not only able to offer important micro attending skills of listening and demonstrating empathy and validation, but are also trained to advocate and empower people.

Some older adults may acquiesce to perceived policies and protocol regarding sexual activity, and as a result, may disregard their own sexual desire. Some may believe that nursing home staff do not consider older adult sexual expression a part of a person's quality of life. Counselors may advocate for more social opportunities for residents to meet others in the nursing home or outside in the community. Counselors may also help to train nursing staff regarding positive sexual expression and may also be in an optimal position to promote sex-positive nursing home reform. For example, it might be beneficial in George's case for him to have staff who not only encourage the viewing of pornographic movies, but also collaborate with him to select a better time to watch the videos.

Moreover, although older adult sexual expression may change over time, it still exists (Lindau et al., 2007), and as a result, we are seeing an alarming rise of sexually transmitted diseases and infections among this population. Counselors have the incredible opportunity to objectively and affirmatively provide comprehensive sex education to older adults residing in nursing home facilities. As a licensed counselor, I would also suggest for nursing homes to develop the following sex-positive practices with counselor support to (1) individually meet with residents upon orientation to discuss sexuality-related rights of residents and to present sexualityrelated opportunities offered by the nursing home, (2) communicate sexuality-related opportunities to residents on an ongoing basis, (3) evaluate sexual needs of clients on a routine basis through surveys, (4) create a library of sexualityrelated videos and literature for resident use including romance novels, (5) provide condoms, dental dams, lubricants, and literature on sexually transmitted infections and diseases to residents who are actively sexual, (6) encourage residents to request information regarding sexual issues with a physician, (7) facilitate community-based events and activities for residents to socialize with other nursing homes, senior centers, and retirement communities, and (8) facilitate in-home activities and workshops on the topic of sexual expression (e.g. a party where someone comes in to talk about arthritisfriendly masturbatory tools and lubricants) and ways to redefine their sexual script.

Lastly, counselors would ideally provide comprehensive sex-positive training for both staff and residents to learn current information on the topic of aging sexual expression. This training could be done individually or in a group setting with residents but should be done as a group with staff, as it is important for all staff members to be on the same page where residents and sexual expression are concerned. Educational intervention training could also be included for staff and residents who display negative attitudes toward sexual expression.

Nursing homes are full of unique individuals with vastly different backgrounds. Therefore, it would behoove nursing homes and counselors to consider sexual expression as a part of resident quality of life. This study suggests that there is an uncommunicated need for residents to express themselves in a way that encourages autonomy, independence, and sexual expression. Every single resident in this study described a disinterest or discomfort in communicating their needs to staff, which could suggest to nursing homes and counselors that more communication on the topic is needed. Of course, the findings from this small sample study cannot be presumed to make a sweeping statement for all residents in all nursing homes. These examples do however speak to how the system of thinking may be different if residents were knowledgeable of specific policies on positive sexual expression and had counselors who could help to empower them to have a voice when it comes to their sexual needs and their need for autonomy and privacy.

\section{Limitations}

Qualitative research offers an incredible opportunity for individual voices to be heard; however, the data is neither generalizable nor comprehensive. The voices of these ten brave individuals cannot account for every older adult who resides in a nursing home. Specifically, these individuals resided in two small Midwestern towns and all participants identified as White. It could be assumed that a more diverse group of people could produce very different data. Additionally, many women in their 70s and 80s embrace their sexual- 
ity (Doll, 2013). In this study, the idea of sexual expression was not heavily considered and two women considered the interest and act of sexual expression unimportant across their lifespan.

Although it is essential for narratives to be heard from the actual voice of the participant, a potential weakness that may exist in this study involves self-reporting. The women in particular were not as forthcoming as had been anticipated, and it is conceivable that if participants believed that reporting of sexual behavior did not align with social expectations, that they might have censored themselves as a result. Finally, although the researcher was critically self-reflective about their own preconceptions and incorporated triangulation, bracketing, member checking, and trustworthiness to confirm and collaborate meaning, researcher bias is a potential limitation in qualitative studies.

\section{Conclusions}

There is limited research, both quantitative and qualitative, on the topic of aging sexual expression; nevertheless, aging sexual expression exists in nursing homes. Counselors and staff are in an ideal position to advocate on behalf of the nursing home resident population, and yet, without the research to support and strengthen communication and policy on healthy aging sexual expression, the desires of the residents will continue to be challenged. This study may be used to expand the knowledge of aging sexual expression specific to the resident community for counselors, nursing home administrators, staff, residents, and family members. Qualitative resources within the nursing home resident experience have primarily focused on the perspective of the staff member. This study was able to take place in a nursing home setting where residents were personally asked questions regarding their sexual interests, desires, concerns, and views on sexuality in general. It included idiographic narratives of individual residents and expounded on their stories as sexual beings, or better yet, as human beings shaped by varying experiences, generational influences, and gender ascription.

\section{References}

Archibald, C. (2002). Sexuality and dementia in residential care-whose responsibility? Sexual and Relationship Therapy, 17(3), 301-309. doi:10.1080/14681990220149103

Beeber, A. (2011). The burden of family caregiving never ends. Blog post. Retrieved from https:// WwW. rwjf . org/en/blog/2011/12/the-burden -of-family-caregiving-never-ends.html

Bell, S., Reissing, E. D., Henry, L. A., \& VanZuylen, H. (2017). Sexual activity after 60: A systematic review of associated factors. Sexual Medicine Reviews, 5(1), 52-80. doi:10.1016/j.sxmr.2016.03.001
Blash, D. L. (2010). Faith in counseling: A qualitative examination of the experiences of african american college students with the integration of religion and spirituality into counseling (Unpublished doctoral dissertation). University of Missouri-St. Louis.

Centers for Disease Control and Prevention. (2018). Sexually transmitted disease surveillance report. Author. Retrieved from https://www.cdc.gov/std/ stats16/default.htm

DeLamater, J. D., \& Moorman, S. M. (2007). Sexual behavior in later life. Journal of Aging and Health, 19(6), 921-945. doi:10.1177/0898264307308342

DeLamater, J. D., \& Sill, M. (2005). Sexual desire in later life. Journal of Sex Research, 42(2), 138-149. doi:10.1080/00224490509552267

Doll, G. M. (2013). Sexuality in nursing homes: Practice and policy. Journal of Gerontological Nursing, 39(7), 30-37. doi:10.3928/00989134-20130418-01

Elias, J., \& Ryan, A. (2011). A review and commentary on the factors that influence expressions of sexuality by older people in care homes. Journal of Clinical Nursing, 20(11-12), 1668-1676. doi:10.1111/j.13652702.2010.03409.x

Haesler, E., Bauer, M., \& Fetherstonhaugh, D. (2016). Sexuality, sexual health and older people: A systematic review of research on the knowledge and attitudes of health professionals. Nurse Education Today, 40, 5771. doi:10.1016/j.nedt.2016.02.012

Hajjar, R. R., \& Kamel, H. K. (2004). Sexuality in the nursing home, part 1: Attitudes and barriers to sexual expression. Journal of the American Medical Directors Association, 5(2), S43-S47. doi:10.1016/s15258610(04)70092-4

Hillman, J. (2000). Clinical perspectives on elderly sexuality. New York: Kluwer Academic/Plenum Publishers.

Hudson, W. W., Murphy, G. J., \& Nurius, P. S. (1983). A short-form scale to measure liberal vs. conservative orientations toward human sexual expression. The Journal of Sex Research, 19(3), 258-272. doi:10.1080/00224498309551186

Hughes, A. K., \& Wittmann, D. (2014). Aging sexuality: Knowledge and perceptions of preparation among u.s. primary care providers. Journal of Sex $\mathcal{E}$ Marital Therapy, 41(3), 304-313. doi:10.1080/0092623x.2014.889056

Kampfe, C. (2015). Counseling older people : opportunities and challenges. Alexandria, VA: American Counseling Association.

Kehoe, L. (2013). Mental health counselors and the long term care system. Blog post. Retrieved from https://www. counseling.org/news/aca -blogs/aca-member-blogs/aca-member-blogs/ 2013/04/08/mental-health-counselors-and 
-the-long-term-care-system

Knaplund, K. S. (2015). The right of privacy and america's aging population. Denver University Law Review, 86, 439-456.

Laflin, M. T. (1996). Promoting the sexual health of geriatric patients. Topics in Geriatric Rehabilitation, 11(4), 4354. doi:10.1097/00013614-199606000-00008

Levkovich, I., Gewirtz-Meydan, A., Karkabi, K., \& Ayalon, L. (2018). Views of family physicians on heterosexual sexual function in older adults. BMC Family Practice, 19(1). doi:10.1186/s12875-018-0770-1

Lindau, S. T., Schumm, L. P., Laumann, E. O., Levinson, W., O’Muircheartaigh, C. A., \& Waite, L. J. (2007). A study of sexuality and health among older adults in the united states. New England Journal of Medicine, 357(8), 762-774. doi:10.1056/nejmoa067423

Mahieu, L., \& Gastmans, C. (2011). Sexuality in institutionalized elderly persons: a systematic review of argument-based ethics literature. International Psychogeriatrics, 24(3), 346-357. doi:10.1017/s1041610211001542

Mann, S. A., \& Kelley, L. R. (1997). Standing at the crossroads of modernist thought: Collins, smith, and the new feminist epistemologies. Gender $\mathcal{F}$ Society, 11(4), 391-408.

Maples, M. F., \& Abney, P. C. (2006). Baby boomers mature and gerontological counseling comes of age. Journal of Counseling $\mathcal{E}$ Development, 84(1), 3-9. doi:10.1002/j.1556-6678.2006.tb00374.x

Masters, W., Johnson, V. E., \& Kolodny, R. C. (1994). Heterosexuality. New York, NY: HarperCollins.

Merriam, S. (2002). Qualitative research in practice : examples for discussion and analysis. San Francisco: Jossey-Bass.

Metzger, E. (2017). Ethics and intimate sexual activity in long-term care. AMA Journal of Ethics, 19(7), 640648.

Moustakas, C. (1994). Phenomenological research methods. Thousand Oaks: Sage Publications.

Mulligan, T., \& Palguta, R. F. (1991). Sexual interest, activity, and satisfaction among male nursing home residents. Archives of Sexual Behavior, 20(2), 199-204. doi:10.1007/bf01541944

Muzacz, A., \& Akinsulure-Smith, A. (2013). Older adults and sexuality: Implications for counseling ethnic and sexual minority clients. Journal of Mental Health Counseling, 35(1), 1-14. doi:10.17744/mehc.35.1.534385v3r0876235

Roberts, A. W., Ogunwole, S. U., Blakeslee, L., \& Rabe, M. A. (2018). The population 65 years and older in the united states: 2016 (Tech. Rep.). United States Census Bureau. Retrieved from https://wWw. census.gov/library/ publications/2018/acs/acs-38.html

Seidman, I. (2013). Interviewing as qualitative research : a guide for researchers in education and the social sciences. New York: Teachers College Press.

Smith, J. (2008). Qualitative psychology : a practical guide to research methods. London Los, Angeles, CA: SAGE Publications.

Solway, E., Clark, S., Singer, D., Kirch, M., \& Malani, P. (2018). Let's talk about sex (Tech. Rep.). University of Michigan Healthy Aging Poll. Retrieved from https://www.healthyagingpoll - org/report/lets-talk-about-sex

Sousa, A. D., Dhingra, I., \& Sonavane, S. (2016). Sexuality in older adults: Clinical and psychosocial dilemmas. Journal of Geriatric Mental Health, 3(2), 131. doi:10.4103/2348-9995.195629

Syme, M. L., \& Cohn, T. J. (2015). Examining aging sexual stigma attitudes among adults by gender, age, and generational status. Aging $\mathcal{G}$ Mental Health, 20(1), 36-45. doi:10.1080/13607863.2015.1012044

Voice, N. C. (2019). Residents' rights. Retrieved from https://ltcombudsman.org/issues/ residents-rights

Watters, Y., \& Boyd, T. V. (2009). Sexuality in later life: opportunity for reflections for healthcare providers. Sexual and Relationship Therapy, 24(3-4), 307-315. doi:10.1080/14681990903398047

Williams, A. P., Lum, J., Morton-Chang, F., Kuluski, K., Peckham, A., Warrick, N., \& Ying, A. (2016). Integrating long-term care into a community-based continuum: Shifting from" beds" to" places". IRPP Study(59), 1-45.

Zeglin, R. J., Dam, D. V., \& Hergenrather, K. C. (2017). An introduction to proposed human sexuality counseling competencies. International Journal for the Advancement of Counselling, 40(2), 105-121. doi:10.1007/s10447-017-9314-y 